\title{
Mole per Milliliter
}

National Cancer Institute

\section{Source}

National Cancer Institute. Mole per Milliliter. NCI Thesaurus. Code C68891.

A unit of concentration (molarity unit) equal to one mole of solute in one milliliter of solution. 